\title{
Discrimination of Excellence: A Research Agenda
}

\author{
Julia M. Puaschunder ${ }^{1,2,3}$ \\ ${ }^{1}$ The New School, Department of Economics, 6 East $16^{\text {th }}$ Street, 9 $9^{\text {rd }}$ floor 89, New York, NY 10003, US A, \\ Julia.Puaschunder@newschool.edu, T001212229 5700,F 001212229 5724,www.juliampuaschunder.com \\ ${ }^{2}$ Columbia University, Graduate School of Arts and Sciences,Julia.Puaschunder@columbia.edu, bttp:/ / blogs.cuit.columbia.edu/jmp2265 \\ ${ }^{3}$ Princeton University, Graduate School of Arts and Sciences,Julia.Puaschunder@princeton.edu
}

\begin{abstract}
Discrimination is unjust or prejudicial treatment of different categories of people or things. Long-standing, ample evidence of discrimination and most important attempts exist to legally abolish, economically counter-weight and societally alleviate the negative impacts of discrimination around the world. Yet to this day, there is hardly any description of discrimination of excellence. Unfair treatment of outperformers occurs when focusing away from merit leads to economic inefficiency based on arbitrary decision making.
\end{abstract}

KEYWORDS: Academia, Discrimination, Economic Disadvantage, Excellence, Outperformers, Teaching, Unjust Treatment

\section{Introduction}

Discrimination is the unjust or prejudicial treatment of different categories of people or things. Longstanding, ample evidence exists of discrimination in our schooling, education, health care, housing, workplace, markets, economy, taxation, democracy, and society-to name just a few areas discrimination touches upon. Discrimination is especially faced by whom social psychologists call 'outgroups'-social groups that are treated differently and face unjustified disadvantages.

Anti-discrimination legislation and public policies to alleviate the negative consequences of discrimination exist around the world.

As a most advanced anti-discrimination effort, the Fifth and Fourteenth Amendments of the United States Constitution outrule the federal and state governments to discriminate. The United States Employment Discrimination laws seek to prevent discrimination based on race, sex, sexual orientation, religion, national origin, physical disability, and age by employers. The United States Equal Employment Opportunity Commission lists as especially sensitive areas of discrimination attention age, disability, equal pay and compensation, genetic information, harassment, national origin, pregnancy, race and color, religion, retaliation, sex and sexual harassment.

In the European world, the European Union first introduced an Anti-Discrimination Directive that would ban discrimination on the grounds of age, disability, religion or belief and sexual orientation in all areas of EU competence. The Lisbon Treaty on European Union and the Treaty on the Functioning of the European Union, which came into binding effect on all European Union member states in 2009 and serves as legal protection against discrimination for all European citizens since then, grounds anti-discrimination laws on the idea of equal rights to be treated unbiased with equal fairness and dignity.

Very many different and most important attempts exist to legally abolish, economically counter-weight and societally alleviate the negative impacts of discrimination around the world. People seem to have a natural inclination towards giving everyone a fair chance to compete and a helping hand to those who appear to not get a fair chance. It ennobles society to treat people with respect and meet them in dignity - even if they may be different.

The American educational world is based on the foundations of merit-based equal opportunity and allows for overcoming discrimination in quota efforts. People from all over the world enter the US educational system as a safe haven of protection from discrimination in the hope to be evaluated based on merit. It appears to be an innate human wish to be given a fair chance to compete without any prejudice and be met with equal fairness and dignity. 
Yet to this day, there is hardly any description of discrimination of excellence or unjust treatment of outperformers, which appears most striking in the educational world. While most important work has been done and should continue on how to overcome discrimination towards outgroups; this article argues for most novel attention to discrimination of outperformers, who - as the paper will outline in data from the higher educational sector and macro-economic modeling - are weakened by unfair discrimination in the wake of their stellar performance shadowing others' relative underperformance. Discrimination based on excellence differs from purely fair competitive contest by the nature of focusing attention away from merit, skills or performance. Performance gets evaluated biased with the view of outperformers lacking social skills and behind-the-back defamation often leads to unfair disadvantages and unjust treatment, such as setting people up as failures, erecting hidden hurdles with intentional glitches and/or prolonged and arbitrary decision making - to name a few discriminatory barriers excellent outperformers face, which are put up by those who fear not being able to keep up with outperformers, who dwarf their performance relatively.

Discrimination of excellence includes the most recent case of standardized admission test outperformers suing a U.S. higher education institution over fair admission standards and admission fraud scandals coupled with an economic modeling of socio-economic losses implied by discriminating against strivers. The societal value of outperformers is outlined in Veblen's trickling down of excellence, The American Dream ideals of striving being an economic driver as well as political science comparisons of different regimes' conduct around excellency. The social psychology categorization of society into so-called 'ingroups' and 'outgroups' is spearheaded with integrating 'übergroups' as natural strivers who face unprecedently captured discrimination. Sociopsychological motives - such as envy, jealousy, inferiority complex, reputation greed and suboptimal group norms - explain discrimination towards outperformance to provide coping and alleviation strategies. Intergenerational aspects and leadership features of discrimination of excellence are proposed.

\section{Research Question}

The research provides a truly heterodox economics standpoint on reconsidering discrimination in a novel light with attention to those who are put down due to their stellar excellence outshining underperformers, whose inappropriate discriminatory conduct deserves to be left behind for the sake of upholding individual well-being derived from dignity, economic prosperity grounded in respect for striving and societal advancement founded on excellency.

\section{Theory}

Theoretically, research should present an overview of the history and conduct around discrimination in society from legal, economic, political and socio-psychological science perspectives with special attention to the United States and Europe.

Discrimination of excellence is introduced from a legal standpoint-including the most recent case of standardized admission test outperformers suing a U.S. higher education institution over fair admission standards and admission fraud scandals - coupled with an economic modeling of socioeconomic losses implied by discriminating and weakening strivers in our society.

The societal value of outperformers will be outlined in Thorsten Veblen's trickling down of excellence argument, The American Dream ideals of constant striving being a motivator and economic driver by aspiration and hope as well as political science theories on capitalist versus communist ideals shaping economic productivity and society.

The research also adds to the political social psychology categorization of society into socalled 'ingroups' and 'outgroups' (Tajfel \& Turner 1979) the theoretical idea of integrating 'übergroups' - natural strivers and outperformers who may face unprecedently captured resistance and discrimination in schooling and higher educational institutions, workplace environments and society. 
In addition, the theoretical part speaks about potential socio-psychological foundations and behavioral economics decision making failures - such as envy, jealousy, inferiority complexes, reputation greed and suboptimal group norms - to explain the hostility towards outperformers. Socio-psychological coping and alleviation strategies are given.

Intergenerational aspects of discrimination of excellence are proposed. While elders may in particular be prone to feel envy of young having accomplished more earlier than them given their shorter time span ahead to make up for underperformance; young may face envy in light of resources being distributed less merit or performance-based but on established hierarchies of seniority.

Lastly, leadership features of discrimination of excellence are introduced. Leaders may fear outperformers in lower hierarchical positions and being shadowed by those whom they should lead and be superior to as a justification for their hierarchical leadership standing.

\section{Results}

Empirically, qualitative case studies, diary technique collected data and an external review report in the higher education sector are advised to be carried out to vividly outline discrimination based on excellence (Study 1). Qualitative analyses of $\mathrm{PhD}$ studies blog entries could reveal a pattern of outperformers being forced out of higher educational institutions to successfully continuing in higherranked institutions (Study 2). Evidence of intangible admission criteria, unfair testing situations and delayed or unsuccessful academic promotion statistics serve as additional evidence on discrimination based on excellence. Resistance to share information on testing and promotion criteria transparently is detected to allow for discrimination (Study 3). Macro-economic analyses reveal industries that are prone to breed discrimination based on excellence (Study 4) to estimate the short and long-term losses of discrimination of excellence based on economic trickling down and too-big-to-fail arguments but also Keynes' multiplier innovatively applied in endogenous growth theory alongside including health and societal risks in the wake of discrimination (Study 5). Macro-economic cross-sectional and time series analyses in the laboratory of modern world history outline socio-economic costs of slowing outperformers and abolishing intellectual advancement (Study 6). Artificial intelligence increasing the currently unprecendently wide divide between skilled and unskilled labor is predicted to even higher importance of attention to excellency in the future (Study 7).

The concrete empirical plan should starts with Study 1 presenting qualitative case studies, diary technique collected data and an external review report in the higher education sector that vividly outline discrimination based on excellence examples. Strategies to slow down or weaken outperformers - such as indirect agency, unresponsiveness, unjustified prolonged decision making, belittling, defamation, behind-the-back reputation destruction, disciplinary punishment, censoring free speech, shaming, bullying, restriction of access to information, resources, leadership and communities as well as unfair competition enacted in arbitrary decision-making, intransparent testing and promotion criteria - are presented. Evidence for destroying the image of outperformers is found based on prejudice against excellence being biasedly pegged to lacking social skills and fit. These hidden tactics are speculated to make individuals who outperform slower, cut them off from access to information, communities, resources and leadership in an attempt to make excellent individuals feel inferior inside as their outside performance trumps and sets higher standards while shadowing the relative underperformance of those around.

Study 2 analyzes contents of $\mathrm{PhD}$ studies blogs qualitatively that reveal a pattern of outperformers and strivers being forced out of educational institutions but successfully continuing on in higher-ranked institutions serving as a natural field experiment and expert evidence of discrimination based on excellence that grants hope of justice over time and merit winning in a more excellent environment. Economic inefficiencies of lost time and career-switching costs but also speculations of unnoticed destruction of human capital of those who may be ashamed and not represented on blogs are mentioned.

Study 3 presents quantitative evidence of tenure track decisions and delayed or unsuccessful academic promotion statistics as additional evidence on discrimination based on excellence in the 
academic world. Resistance to share data on promotion criteria transparently, unfair testing situations and intangible admission criteria are detected as critical career gatekeeping events, in which outperformers seem to underperform due to an unfair discrimination bias.

Study 4 provides a macro-economic analysis of what industries are prone to breed discrimination based on excellence. Institutions that face competition from outside contestants but also competition within institutions over scarce resources that have merit-based up-or-out placement criteria in structuring hierarchical rank orders yet performance being partially measured on intangible or intransparent performance criteria appear to be prevalent to breed discrimination based on excellence.

Study 5 estimates in macro-economic modeling societal short-term and long-term losses due to curbed excellent performance alongside integrating the social, socio-psychological and emotional burdens that may hold health and societal risks in the wake of discrimination. A macro-economic estimate of the societal losses and risks in the wake of discriminating against those who outperform and accomplish more than average is given based on the economic trickling down and too-big-tofail arguments but also Keynes' multiplier, which are-for the very first time-applied on endogenous growth theory labor components.

Study 6 provides macro-economic cross-sectional but also time series analyses in the history of modern economies what social costs and economic consequences slowing down outperformers and abolishing intellectual advancement have. Cambodia, East versus West Germany but also former Eastern European countries' regimes attempts to kill, cut down or slow economic performance and individual striving provide shocking examples what discrimination of excellence could do to individuals, countries, democracies and society in the laboratory of world history.

Study 7 grants a future prospect in the age of artificial intelligence. The socio-economic divide between skilled and unskilled labor gratification has never been higher as of now. This is seen as a sign of a currently ringing-in artificial intelligence revolution. With artificial intelligence entering the workforce, future success is speculated to be dependent on creative excellency. Currently captured trends of slowbalization - the slowing of globalization - and reshoring - as the countertrend to offshoring and outsourcing to low-income countries during the golden era of globalization being relocating to high-tech artificial intelligence hubs - are expected to increase competition over knowledge and excellence. Individual workgroups, educational institutions, countries and societies who allow discrimination of excellent outperformers are expected to fall behind as we compete already now and even more so in the future to come with artificial superiority on excellency.

\section{Discussion}

The research agenda may generate novel recommendations on legal codifications, economic action and public policy making as well as corporate workplace incentives to foster performance free from discrimination. Outperformers and underperforming segments should transfer coping in lieu of performance strategies and strategically align in the striving towards a discrimination-free economy and society. Innovatively the project presents that excellence should become part of the especially screened and protected areas of discrimination secured by law and tackled by economic policy action, especially in light of the social, economic and societal losses and downfalls that this paper unprecedently highlights in a multi-faceted way. In order to overcome a further societal stratification and performance polarization between übergroups and outgroups, the project finally argues that outperformers and potentially underperforming segments due to discrimination should transfer coping strategies in lieu of performance strategies and strategically align in the striving towards a discrimination-free workplace, economy, democracy and society. Awareness building, transparency as natural disinfectant and mandatory access to information on hiring, testing and promotion criteria appear as natural and fast, relatively-affordable and easily-implementable remedies besides legal action to combat excellencydiscriminating individuals and institutional structures. Cultures-of-excellence safe havens but also rescue funds for those whose career has taken a hit due to their outperformance are additional innovative discrimination alleviation strategies proposed. As one of the most vulnerable assets of an economy and 
society, excellency should be cherished and protected from discrimination and treated with equal respect and dignity.

In total, the project provides a truly heterodox economics standpoint on reconsidering discrimination in a novel light with attention to those who are put down due to their stellar excellence outshining underperformers, whose inappropriate discriminatory conduct deserves to be left behind - for the sake of upholding individual well-being derived from dignity, economic prosperity grounded in respect for striving and societal advancement founded on excellency.

\section{References}

Tajfel, H. \& Turner, J. C. 1979. "An integrative theory of intergroup conflict.” In W. G. Austin \& S. Worchel (Eds.), The Social Psychology of Intergroup Relations. Monterey, CA: Brooks-Cole. 